\title{
GT2012-69175
}

\section{MODELLING RAIN DROP IMPACT OF OFFSHORE WIND TURBINE BLADES}

\author{
M. H. Keegan \\ Wind Energy Systems CDT \\ University of Strathclyde \\ United Kingdom
}

\author{
D. H. Nash \\ Department of Mechanical and \\ Aerospace Engineering \\ University of Strathclyde \\ United Kingdom
}

\author{
M. M. Stack \\ Department of Mechanical and \\ Aerospace Engineering \\ University of Strathclyde \\ United Kingdom
}

\section{ABSTRACT}

The effects of rain and hail erosion and impact damage on the leading edge of offshore wind turbine blades have been investigated.

A literature review was conducted to establish the effects of exposure to these conditions and also to investigate the liquid impact phenomena and their implications for leading edge materials. The role of Explicit Dynamics software modelling in simulating impact events was then also established.

Initial rain impact modelling is then discussed with the results showing good agreement with theoretical predictions both numerically and with respect to the temporal and spatial development of the impact event. Future development of the rain model and a proposed hail model are then detailed.

Planned rain impact and erosion testing work is addressed which will be used to validate, inform and compliment the ongoing modelling efforts.

\section{NOMENCLATURE}

$P \quad$ Pressure

$\rho \quad$ Density

$c \quad$ Speed of sound

$V \quad$ Velocity

$F \quad$ Impact Force

$m \quad$ Mass

$d \quad$ Droplet diameter

SPH Smooth Particle Hydrodynamics

\author{
Subscripts \\ $0 \quad$ Undisturbed fluid \\ $l \quad$ Liquid medium \\ $s \quad$ Solid Medium
}

\section{INTRODUCTION}

In recent years the growth of UK installed wind energy capacity has been encouraged by the governments low carbon transition plan which aims to deliver $20 \%$ of the UK's energy demands from low carbon sources by the year 2020 [1]. This translates into approximately $30-40 \%$ of the UK's electricity demands being met by renewable sources.

As arguably the most mature renewable technology (compared to wave, tidal and others), wind energy will play a vital role in the development of a Low Carbon energy mix in the UK. The current total installed capacity of wind energy in the UK is approximately 5.7GW [2] representing a significant proportion of the overall national grid capacity which is approximately $80 \mathrm{GW}$. However it is clear that in order for the target of approximately $30 \%$ of energy demand being met by renewable sources circa 2020, there is still a substantial requirement for growth.

In addition to the installed capacity, there is currently approximately $3.4 \mathrm{GW}$ of capacity under construction, $5.4 \mathrm{GW}$ consented and a further $8.9 \mathrm{GW}$ of projects in planning [2], equating to a maximum possible proposed installed capacity of 23.4GW currently under consideration; thus giving an indication of the current ambition and direction of the role of wind energy in the UK. 


\section{Going Offshore}

Onshore wind farm installations currently account for $4.2 \mathrm{GW}$ of the $5.7 \mathrm{GW}$ of total wind capacity. This dominance is attributed to absence of many difficult challenges that face design, installation and operation when considering offshore locations. However in order to achieve the ambitious 2020 targets a significant amount of wind energy will be installed at offshore locations, with $2 \mathrm{GW}$ of offshore projects currently under construction, $1.7 \mathrm{GW}$ consented and $1.9 \mathrm{GW}$ in planning.

Given the often remote siting of offshore installations there are many benefits associated with the deployment of offshore wind energy. One such benefit is that due to the location of offshore sites - often not visible from the shore many environmental planning issues (relating to wildlife, ecology and neighbouring residential areas) are not of concern. As a result, more freedom is afforded to developers when planning an offshore installation in relation to such design variables as hub height, blade length, noise emissions, the number of turbines and blade tip speed (relevant to impact studies).

One of the major factors in offshore wind turbine design is the materials employed in the design and their appropriateness. In particular there is very little published understanding of the performance of typical materials employed on the leading edge of wind turbine blades in relation to their durability over the lifetime of the wind turbine (i.e. resistance to rain, hail and other forms of impact), which are commonly expected to last 20-30 years in useful operation [3]. As an obviously integral component in the wind turbine design, any material failure on the leading edge may have a severe impact on the performance, operational time and therefore efficiency of a wind turbine design.

The following discusses the phenomena of rain impact damage on the leading edge of wind turbine blades; drawing on developed knowledge in similar aerospace studies. The different methods of impact modelling are reviewed and discussed and the industry standard rain erosion test methods are investigated. The methodology and results of preliminary rain impact modelling work are then detailed and the proposed future modelling and testing work described.

\section{LEADING EDGE EROSION AND IMPACT DAMAGE}

As wind turbines and their blades grow larger and longer the tip speed of blades will continue to grow. Table 1 shows some of the characteristics of utility scale turbines, including their tip speeds.
Table 1. TOP TEN (by market share) TURBINE MANUFACTURERS AND THEIR TIPS SPEEDS, SOURCE: [4]

\begin{tabular}{|c|c|c|c|c|c|c|c|c|c|}
\hline & & $\begin{array}{l}\text { Share } \\
\text { cent] }\end{array}$ & [per Model & $\begin{array}{l}\text { Drive } \\
\text { train }\end{array}$ & $\begin{array}{l}\text { Power } \\
{[\mathrm{kW}]}\end{array}$ & rating & $\begin{array}{l}\text { Diameter } \\
{[\mathrm{m}]}\end{array}$ & $\begin{array}{l}\text { Tip } \\
{[\mathrm{m} / \mathrm{s}]}\end{array}$ & $\begin{array}{l}\text { Power } \\
\text { conversion }\end{array}$ \\
\hline 1 & Vestas & 22.8 & V90 & Geared & 3,000 & & 90 & 87 & Asynchronous \\
\hline 2 & $\begin{array}{l}\text { GE } \\
\text { Energy }\end{array}$ & 16.6 & $2.5 \mathrm{XL}$ & Geared & 2,500 & & 100 & 86 & $\begin{array}{l}\text { PMG } \\
\text { converter }\end{array}$ \\
\hline 3 & Gamesa & 15.4 & G90 & Geared & 2,000 & & 90 & 90 & DFIG \\
\hline 4 & Enercon & 14.0 & E82 & Direct & 2,000 & & 82 & 84 & Synchronous \\
\hline 5 & Suzlon & 10.5 & S88 & Geared & 2,100 & & 88 & 71 & Asynchronous \\
\hline 6 & Siemens & 7.1 & $3.6 \mathrm{SWT}$ & Geared & 3,600 & & 107 & 73 & Asynchronous \\
\hline 7 & Acciona & 4.4 & $\begin{array}{l}\text { AW- } \\
119 / 3000\end{array}$ & Geared & 3,000 & & 116 & 74.7 & DFIG \\
\hline 8 & Goldwind & 4.2 & REpower750 & Geared & 750 & & 48 & 58 & Induction \\
\hline 9 & Nordex & 3.4 & N100 & Geared & 2,500 & & 99.8 & 78 & DFIG \\
\hline 10 & Sinovel & 3.4 & $\begin{array}{l}1500 \\
\text { (Windtec) }\end{array}$ & Geared & 1,500 & & 70 & & \\
\hline
\end{tabular}

As can be seen the tip speeds can be up to $90 \mathrm{~ms}^{-1}$ and as the technology develops and grows larger these values will further increase; especially in an offshore environment when the noise created by high tip speeds is of little concern [5]. Coupling this $90 \mathrm{~ms}^{-1}$ tip speed with a strong $25 \mathrm{~ms}^{-1}$ operational wind speed could result in a maximum impact velocity for rain (and hail) well in excess of $100 \mathrm{~ms}^{-1}$.

In the offshore operating environment there are several possible environmental factors which could affect the integrity of the blade leading edge with respect to impact and erosion. Firstly, as detailed, rain impingement on the blade leading edge will occur frequently throughout the turbines operational life, striking the blade with velocities of up to and potentially in excess of $100 \mathrm{~ms}^{-1}$. It may also be the case that during the turbines lifetime it may be exposed (more infrequently) to sea spray whipped up from the water surface below which may strike the blade in large splashes; this may be more frequent at near shore locations where the sea water breaks and splashes. In near shore locations there may also be issues with sand impingement where sand is carried from the shore to the turbine operational area. Although sand and dust impingement in the offshore environment is more unlikely, the threat to the integrity of the blade surface posed by such exposure is significant (as will be illustrated in the following section). Finally, one of the most potentially damaging weather conditions will arise from hail storms and subsequently high speed hail impact on the blade leading edge. Given the increased average diameter of a hail stone when compared to a rain drop and consequently the increased terminal velocity, a typical hailstone impact event will be significantly more violent than water impact.

The current focus of this research effort is to address and assess the effects of rain droplet impingement on the blade. However, it is hoped that future efforts will look at the effects of both hail and sea-spray impact (as detailed later).

As mentioned above, there is little available literature that expressly addresses the issue of leading edge erosion of wind turbine blades. It is only mentioned anecdotally in some publications and stated as a problem by some manufacturers and blade repair companies.

A photograph from Sandia National Laboratory [6] (Fig.1) is given as an example of severe leading edge erosion. 


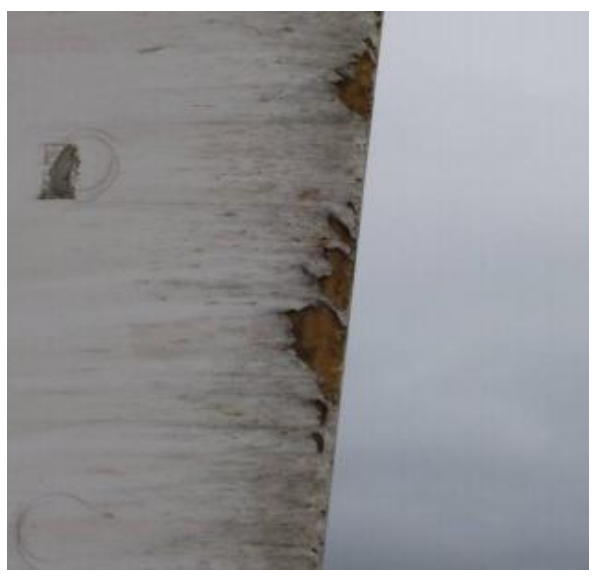

Figure 1. LEADING EDGE EROSION (presented without scale), SOURCE: [6]

As can be seen, a significant amount of the surface coating has been eroded away, leaving the laminate underneath exposed and vulnerable to damage. It is not stated however what form of erosion was likely to have taken place on this blade, but the morphology of the surface would suggest sand impingement erosion.

Some blade repair and service companies also provide images of damage on blade leading edges prior to repair, such as the leading edge erosion shown in Fig. 2.

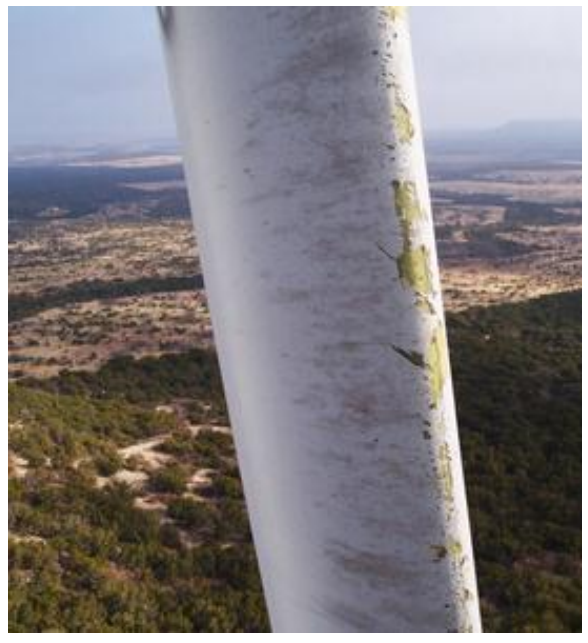

Figure 2. LEADING EDGE EROSION (presented without scale), SOURCE: [7]

The source of the erosion is not given but it may be reasonable to assume that sand and dust impingement played a significant role in the wear process.

Another service and repair firm, Ropeworks [8] also host images of typical leading edge erosion damage found on wind turbine blades on their website, as shown in Fig. 3.
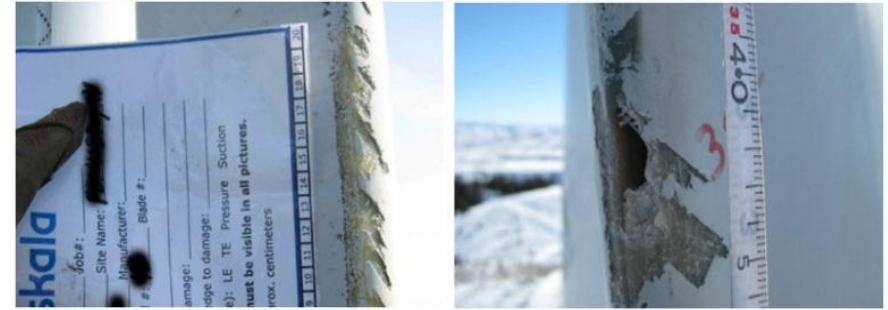

Figure 3. SLIGHT LEADING EDGE EROSION AND POTENTIAL THROUGH LAMINATE DAMAGE CAUSED, SOURCE: [8]

As can be seen the potential effects of leading edge erosion can cause significant damage to the leading edge of the blade and potentially erode through to the laminate below the surface coating. Such damage could develop further through water and humidity ingress into the composite shell (degrading the mechanical properties) and potentially through ice freezethaw cycles in the cracks and crevices created.

Damage created on the upper surface of the blade may not be the exclusive damage process for blade leading edges, as it has been shown in aerospace studies that in composite materials sub-surface damage can occur with little-to-no indication of damage on the surface [9], as shown in Fig. 4.

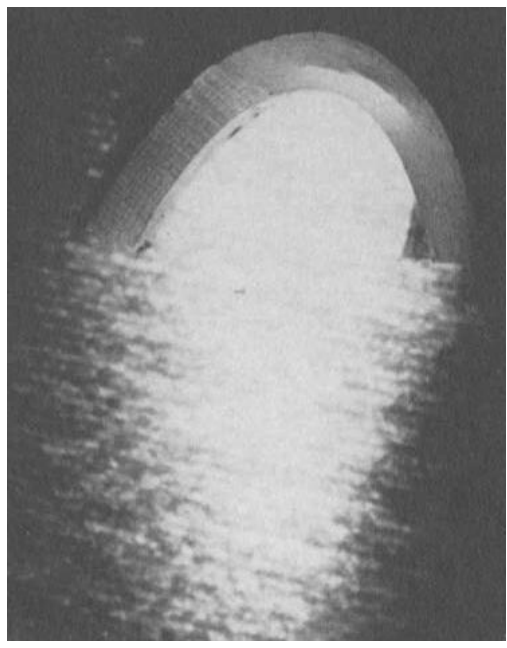

\section{Figure 4. CROSS SECTION OF SUBSURFACE DAMAGE CAUSED BY 223 $\mathrm{ms}^{-1}$ IMPACT SPEED, SOURCE: [9]}

The blade sample shown in Fig. 4 was exposed to simulated rain impingement at $25.4 \mathrm{mmh}^{-1}$ at a speed of $223 \mathrm{~ms}^{-1}$ for 180 minutes using apparatus discussed later (Fig. 9). From the image it can be seen that subsurface laminate and interlaminate cracking (shown by the light areas in the crosssection) occurred as a result of exposure

These delaminations occurred only in the lower levels of the composite plies but no sign of damage was shown on the surface blade section as a result of the tough but brittle material behaviour of the composite. 
This form of hidden sub-surface damage in brittle composite materials is of course of concern in a wind turbine application (as discussed in the following section) and therefore highlights the further need for greater understanding of the possible damage mechanisms in wind turbine leading edge component materials.

\section{BLADE MATERIALS}

Modern turbine designers and blade manufacturers recognise the need for blades to possess a high specific strength (strength to weight ratio) in order to span the large distances required and deliver sufficient strength and stiffness without large root bending moments that would be associated with heavier materials.

Composite materials or more specifically fibre reinforced plastics, can deliver these high specific strength characteristics due to their low weight and high strength/stiffness as shown in Fig. 5; only outperformed in this regards by more costly and brittle ceramic materials.

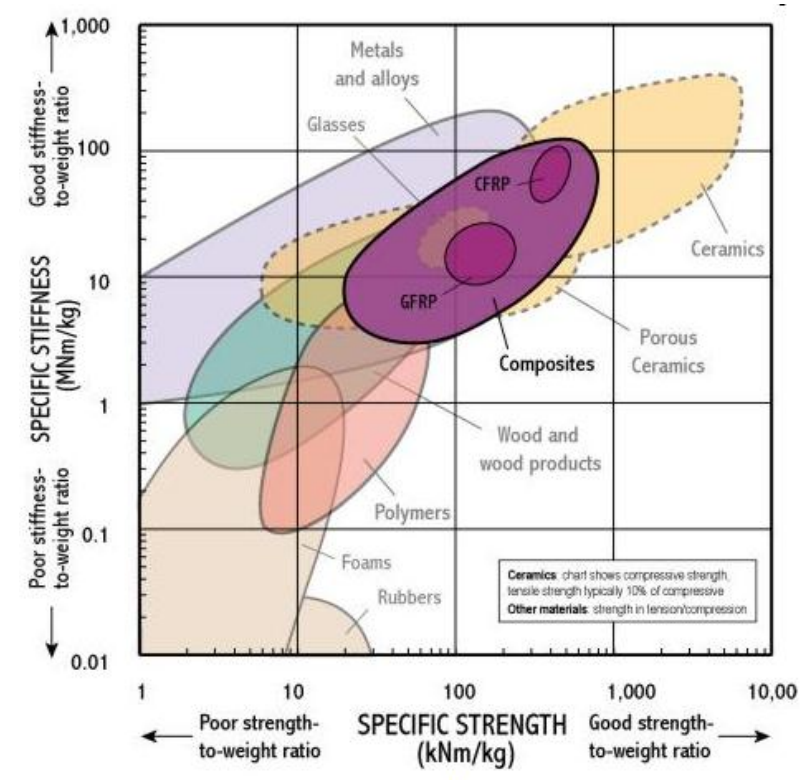

A

Figure 5. SPECIFIC STRENGTH AND STIFFNESS OF NUMEROUS ENGINEERING MATERIAL CLASSES [10]

As a result of these attractive specific strength and stiffness properties the use of composite materials has come into prominence in modern wind turbine designs. The composite material may take the form of glass reinforced (thermosetting) plastics (GFRP), wood/fibre reinforced plastic hybrids or in some cases carbon fibre reinforced plastic. Many designs utilise a sandwich concept of employing both GFRP and wood (most commonly balsa) laminates to create greater thicknesses in areas of the blade structure susceptible to buckling loads [11].

Glass fibre reinforced thermoplastics such as epoxy or polyester resins are currently the most commonly employed material for utility scale wind turbines featuring in designs by
Enercon [12] and Siemens [13] to name a few. However some manufacturers such as Vestas [14] are now incorporating Carbon fibre reinforced plastics in their blade designs through manufacturing innovations which make the material technology more economically viable.

Although the implementation of thermosetting composites can deliver numerous benefits in wind turbine blade design (relating to strength, stiffness etc.) the main drawback in relation to impact is the manner in which damage is created in the material. Due to the high stiffness and toughness of thermosetting composites, the main method of material failure occurs in the form of brittle cracking which can be difficult to detect on the blade surface with the naked eye.

However there are some material technologies which have been developed to tackle this issue of brittle failure - such as leading edge tapes - that seek to address the issue of damage to the leading edge as discussed in the following section.

\section{Surface Coatings}

As is often the case with design and material selection in a commercial arena the exact choices made by individual wind turbine blade manufacturers are often difficult to ascertain as a result of intellectual property restraints. However, it is suggested that there are two general surface coating systems that are commonly employed, either:

- Gelcoat - An Epoxy or polyester based coating that can be applied in mould during the manufacturing process if using polyester or painted on if using epoxy [15].

- Polyurethane Coating/Paint - A polyurethane based surface coating can be applied to the surface through spraying [15].

However there exists a certain amount of ambiguity in the terminology associated with the technologies and as such they are often bracketed under the common name of gelcoat.

The benefits of employing (poly) urethane coatings are given as: high impact resistance, shape memory as a result of high elasticity, resistant to gouging and abrasion and more [16] [17]. It is suggested that the highly elastic material response helps to dissipate impact energy and stress through allowable deformation. Enercon state in their wind turbine product brochure that they employ a two component polyurethane coating system [12], however in the technical specifications given by many other manufacturers the surface coating is either listed simply as a gelcoat or paint with no material definition.

\section{Leading Edge Tapes}

In locations where the threat of leading edge erosion is significant as a result of a dusty or sandy operating environment the additional application of leading edge tapes on wind turbine blades are utilised. $3 \mathrm{M}$ and Rope Partner are currently collaborating on a study looking at the benefits in terms of power output from a turbine with 3M's leading edge tape [18] applied to the leading edges of the blades [19]. The tapes are made of polyurethane elastomers similar to those implemented in some surface coatings as previously discussed 
and are stated to possess enhanced impact, abrasion and wear properties, illustrated by the tested samples shown in Fig 6.

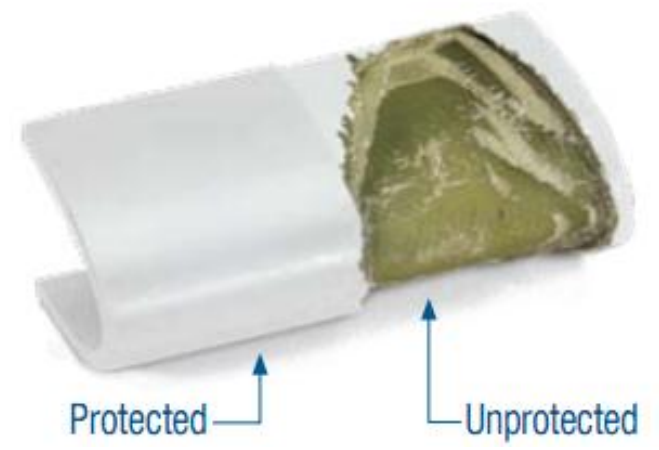

Figure 6. SAMPLE TESTED IN RAINFALL OF ONE INCH PER HOUR AT 500MPH AT THE RAIN EROSION TEST FACILITY, UNIVERSITY OF DAYTON, SOURCE: [20]

The sample in Fig. 6 shows the extensive damage imposed on the surface of the uncoated sample when exposed to accelerated rain erosion testing of one inch per hour at $500 \mathrm{mph}$, at the Rain Erosion Test Facility at the University of Dayton, USA [21], which will be discussed later.

There are numerous other leading suppliers with their own leading edge coating technologies such as Relius (BASF) [22], Tesa [23] and many others, all aiming to address the issue of leading edge erosion.

\section{LIQUID IMPACT}

Liquid impact occurs in countless engineering applications in various mechanisms with varying severity. With respect to wind energy applications the most frequent liquid impact event relates to rain impact on the exposed surfaces of the wind turbine blade. In order to understand the nature in which these impact events occur, a fundamental understanding of the process in which liquid impacts on a solid surface is first required.

\section{Analytical Expressions}

When estimating the impact pressure created by an impinging liquid droplet or jet onto a solid surface, a first approximation is often gained through the waterhammer equation [22] as detailed in Eqn. 1.

$$
P=\rho_{0} c_{0} V_{0}
$$

Where $P$ is the pressure created by the impact, $\rho_{0}$ is the undisturbed water density and $\mathrm{c}_{0}$ is the undisturbed speed of sound in the liquid. The equation was developed for calculating the waterhammer pressure in piping systems and makes the following assumptions:

1. The impact event is one dimensional

2. The target surface is rigid

3. The water density is constant

4. The speed of sound is constant
These are quite fundamental assumptions and are of course not fully compatible with the droplet impact events under consideration in this study, however it is thought that the expression can provide some indication of the magnitude of the pressure acting on the target. The equation also does not take into account shockwave propagation through the target, which is addressed through altering the expression to the form given in Eqn. 2 [23].

$$
P=\frac{V \rho_{l} c_{l} \rho_{s} c_{s}}{\rho_{l} c_{l}+\rho_{s} c_{s}}
$$

Where the subscripts 1 and s refer to the impacting liquid and target solid respectively. These equations give an indication of the pressure generated during the initial phase of droplet impact before lateral flow jetting from the droplet occurs.

With respect to the impact force imparted by an impinging water droplet onto a solid target body, the following relationship has been developed in previous studies [24] [25].

$$
F=\frac{m V^{2}}{d}
$$

This is a fairly rudimentary relationship based on classical mechanics and makes several simplifying assumptions - mainly that the impact event and the maximum force imparted is instantaneous - but can be used as a general indicator of an instantaneous impact force.

\section{Impact Development}

As detailed, there exists a set of equations that can help to describe the pressure developed during the initial phase of liquid droplet impact; however this only represents a certain window of the impact event. The initial phase consists of the leading part of the droplet coming into contact with the solid surface and thus the subsequent development of the waterhammer pressure as described by the equations given. At this point of initial impact a shockwave is reflected from the solid surface and back into the droplet, eventually spreading to the periphery of the contact area between the droplet and the surface, as shown in Fig. 7.

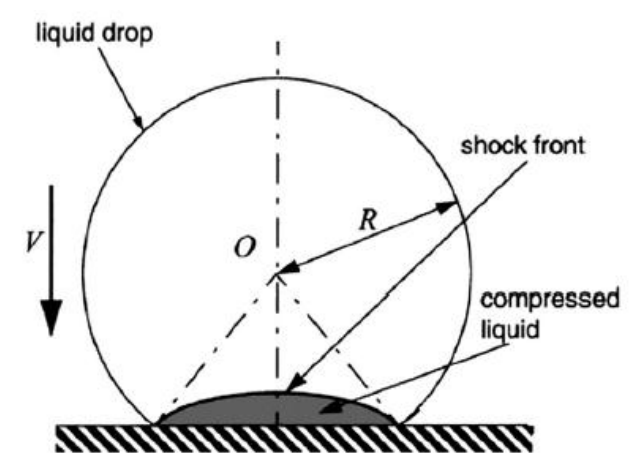

Figure 7. SHOCKWAVE PROPAGATION THROUGH THE LIQUID DROPLET, SOURCE: [26] 
This is a critical point in the impact process as this defines the transition (before lateral jetting) where the waterhammer equations are applicable up to. Once the shockwave propagates out of this area, lateral jetting occurs across the surface and the droplet begins to spread. At this transition point it has been found that the pressure generated begins to rise rapidly to values approximately three times greater than those generated by the waterhammer pressure for a short instance located at the periphery of the droplet contact area (i.e. in a ring shape) [22]. As with any engineering materials the presence of sharp spikes in load extremely undesirable especially with respect to fatigue performance, and if it is assumed that this spiking behaviour occurs routinely during liquid impacts, it may indeed represent a considerable threat to material performance.

It is prudent to note that using the waterhammer equation with an impact speed of $100 \mathrm{~ms}^{-1}$, a water density of $1000 \mathrm{kgm}^{-3}$ and a speed of sound in water of $1400 \mathrm{~ms}^{-1}$ gives an impact pressure of $140 \mathrm{MPa}$ which is considerable given the high frequency associated with this loading throughout the life if the blade.

\section{Damage Mechanism}

The way in which damage is created on a surface due to liquid droplet impact depends on both the nature of the impact (impact velocity and inclination) and the target material.

Figure 8 shows the typical damage formation caused by repeated liquid impact on a ductile target material.

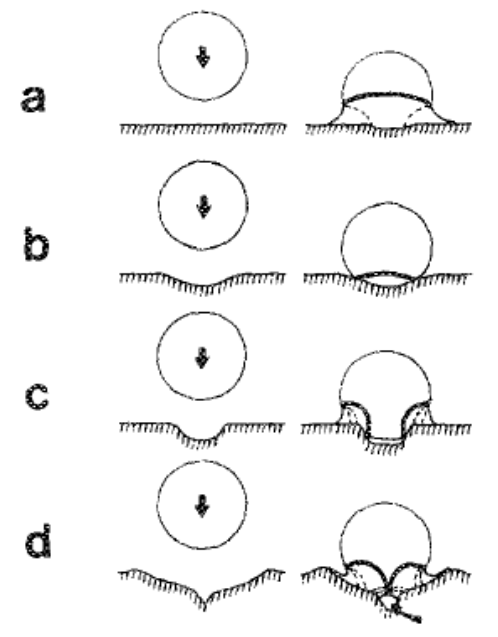

\section{Figure 8. DUCTILE SURFACE EXPOSED TO REPETITIVE DROPLET IMPACT, SHOWING THE FORMATION OF DAMAGE, SOURCE: [27]}

As illustrated, the initial impact events begin to create small indented craters on the surface and this is subsequently deepened through further exposure to impact. This topological change then begins to influence the shock wave behaviour in the impacting droplet and consequently the loading pattern exerted on the surface. In turn this results in stress concentrations in the material worsening the damage process and removing material.
Brittle target materials will respond to droplet impact in a stiffer manner with little to no surface deformation before the onset of damage which occurs in the form of cracking and subsequent material removal.

\section{MODELLING METHODS}

When modelling high-speed, short-duration impacts events the three most commonly applied modelling techniques are:

1. Finite Element Modelling (Lagrangian) - Standard finite element techniques which utilise standard Lagrangian meshing methods (whereby the mesh is applied to the model geometry) are widely used in impact studies. However, in situations where large deformations are likely to occur (i.e. ice and rain impact); issues with the associated over-deformation of the mesh can cause problems leading to cell degeneration in the mesh and therefore a reduction in the model accuracy and increase in computational requirements. As such the Lagrangian technique is limited to modelling impact events where large deformations are unlikely.

2. Eulerian and Eulerian/Lagrangian Methods - This method makes use a Lagrangian method to mesh and model the solid target body (low deformation) but utilises an Eulerian approach to modelling the projectile.

The Eulerian approach differs in that instead of applying a mesh to the geometry concerned, a volume in the model is set as Eulerian domain and a mesh is created in this volume. Therefore, when a body passes through or deforms in the Eulerian domain, the body adopts the Eulerian mesh (or nodes) and continues to adopt new nodes in the mesh as it travels through or deforms. This approach means that even if the original geometry becomes highly deformed the mesh used by the geometry will remain uniform and not experience large deformations.

In theory, simulations can be conducted wherein the Eulerian domain meshes the whole model (i.e. also the target body), however this requires considerable computational power whilst delivering little benefit in terms of the model accuracy compared to the Eulerian/Lagrangian method.

A further variation of this method is the Arbitrary Lagrangian Eulerian approach whereby the Eulerian domain does not only occupy a fixed space in the model but instead moves (Arbitrarily) to optimize the shape of the elements within the domain.

3. Smoothed Particle Hydrodynamic - Smoothed Particle Hydrodynamic (SPH) modelling is a mesh-less method of impact modelling, originally developed for astrophysical and cosmological studies [28]. Instead of a mesh of cells, the material medium is represented by numerous small particles endowed with mass. There is no direct connectivity between the particles instead the method is based upon an interpolatory scheme based on the kernel function. The method has been used in many applications looking at high speed impact 
phenomena such as hail impact and bird strike on aircraft components.

These three variations have been implemented in previous hail impact analysis studies [28] [29] with each method providing accurate (experimentally validated) results. However, due to the occurrence of high mesh deformation the use of the pure Lagrangian approach results in higher computational requirements and therefore longer running times. Therefore, it is proposed that the best modelling methods for the purpose of high deformation impact modelling are the Eulerian methods or the SPH approach; with SPH requiring the shortest run times [28].

\section{TESTING METHODS}

As with many aspects of this research, literature from aerospace studies investigating rain and hail impact on aircraft leading edge components provided useful transferable knowledge and information in relation to wind turbine blades leading edge impact. For this reason the experimental methods used to investigate rain and hail erosion in aerospace studies were examined.

One of the longest serving and most established aerospace rain erosion facilities is the Rain Erosion Test Facility, hosted at the University of Dayton Research Institute (UDRI), Ohio [21], which has been in operation on both an academic and commercial basis for 35 years and claims to be the national and international standard for testing the rain erosion resistance of aerospace materials. The testing apparatus and associated support equipment are shown in Fig. 9.

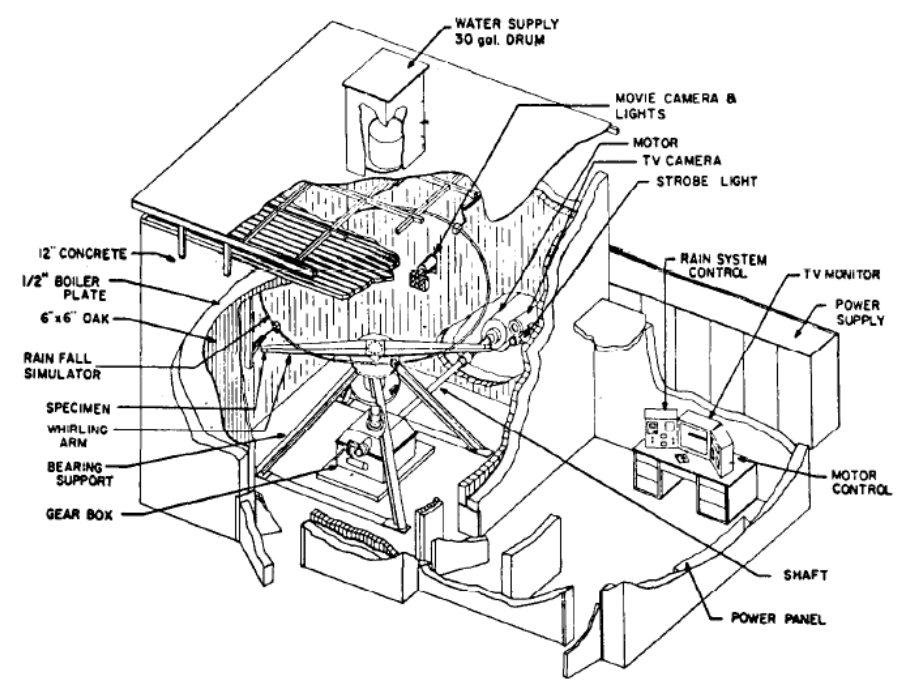

Figure 9. UDRI RAIN EROSION TEST FACILITY, SOURCE: [9]

The facility features a $2.5 \mathrm{~m}$ diameter rotating arm upon which the test sample are mounted on the tips, the arm is driven by a 400hp motor through a gear box which can deliver a maximum tip speed of $400 \mathrm{~ms}^{-1}$ (excessive for the purpose of this study) [9]. The rain fall is simulated by an aluminium pipe annulus mount above the swept path of the rotating arm and fitted with 96 equally spaced hypodermic needles calibrated to deliver a rainfall rate of $25.4 \mathrm{mmh}^{-1}$ with a droplet diameter in the range of $1.5-2 \mathrm{~mm}$. The facility also utilises high speed photography equipment to record the impact events on the sample surface.

As mentioned, the facility has been used extensively in aerospace applications and as detailed previously also in a wind turbine study testing leading edge tapes (Fig. 6).

A similar facility is also currently under development at the Composites Research Centre at the University of Limerick [30], name the Whirling Arm Rain Erosion Rig (WARER) as shown in [33] Fig. 10.

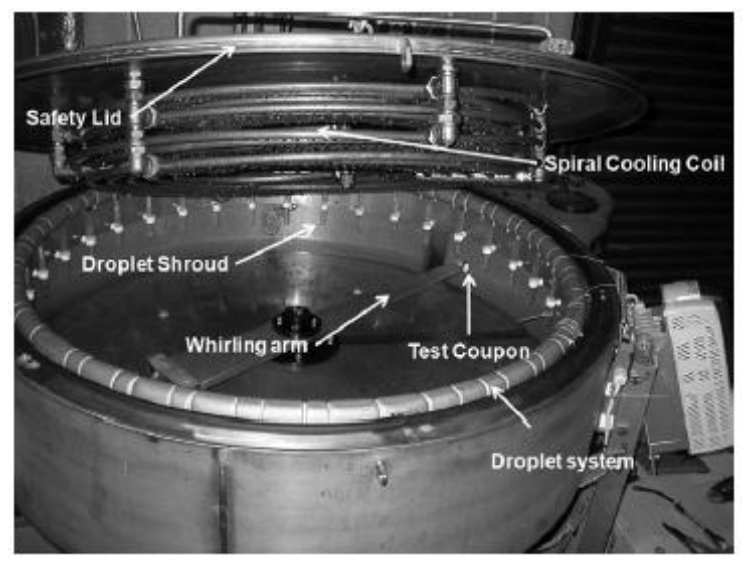

Figure 10. RAIN EROSION TEST APPARATUS, UNIVERSITY OF LIMERICK, SOURCE: [31]

This apparatus works on a similar principle to that of the UDRI facility, using a spinning 600mm diameter arm sample mount passing through a series of spray heads with a rain fall rate of $25.4 \mathrm{mmh}^{-1}$ and an impact speed of up to $129 \mathrm{~ms}^{-1}$.

An alternative method in creating droplet impact events in a controlled manner is to fire a jet of water towards the target and then repeatedly disrupt the jet, thus breaking the flow up into smaller sections (or drops). One such facility that employs this method is the Pulsating Jet Erosion Test Rig (PJET) at EADS IW, Munich, as illustrated in Fig. 11.

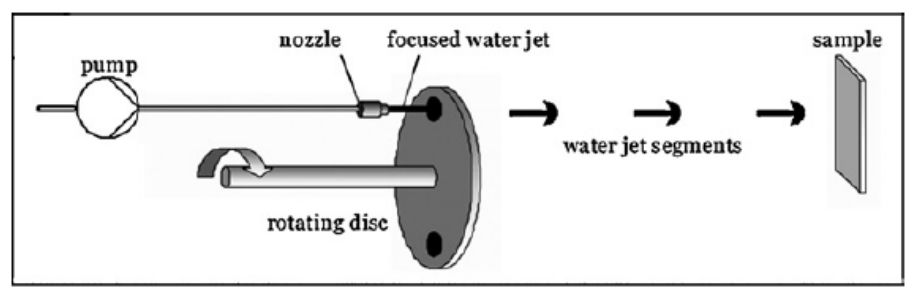

Figure 11. PULSATING JET EROSION TEST RIG (PJET), SOURCE: [31] 


\section{MODEL DEVELOPMENT}

Drawing from the findings in previous literature (as discussed) it was decided that in order to model the impact events under consideration, a combined Eulerian/Lagrangian approach would be implemented. The modelling work documented in this paper details the preliminary efforts to develop and apply the Eulerian/Lagrangian approach to rain impact events. The Explicit Dynamics tool in ANSYS was used to model and solve the simulations.

\section{Impact Characteristics}

The primary objective of the initial modelling work was to establish an accurate rain drop model which could then be used in more elaborate and focussed simulations. For this reason the target material in the initial model was arbitrary as its only purpose was to remain comparatively stiff under the impact of the liquid drop; the characteristics of the impact event are given in Table 2.

Table 2. IMPACT CHARACTERISTICS

\begin{tabular}{|l|l|}
\hline Rain drop diameter & $3 \mathrm{~mm}$ \\
\hline Plate dimensions & $6 \times 6 \times 2 \mathrm{~mm}$ \\
\hline Plate material & Epoxy Resin \\
\hline Impact speed & $30-140 \mathrm{~ms}^{-1}$ \\
\hline Simulation duration & $1.1-1.8 \mu \mathrm{s}$ \\
\hline Plate Lagrangian mesh type & Hexahedral \\
\hline Lagrangian mesh element size & $6 \times \mathrm{E}-5 \mathrm{~m}$ \\
\hline Total Elements & 2602506 \\
\hline Euler domain dimensions & $3.2 \mathrm{E}-3 \mathrm{~m}$ \\
\hline Cell total in domain & 700,000 \\
\hline
\end{tabular}

The material model chosen for the rain drop was the 'WATER' model which is predefined in the ANSYS material library and uses a shock equation of state. The droplet was to travel normal to the target surface, therefore creating a direct impact situation. The target material chosen was an ANSYSpredefined Epoxy resin model and the plate was given dimensions of $6 \times 6 \times 2 \mathrm{~mm}$. The simulation was run across a range of impact velocities from $30-140 \mathrm{~ms}^{-1}$ in order for the results to be compared and validated against the values obtained from the analytical expressions given in Eqn. 1, 2 \& 3.

\section{Pre-processing}

The geometry modelling process was a straightforward process due to the simple nature of the geometry and was performed in the Design Modeller tool in ANSYS. As previously discussed, it was decided an Eulerian/Lagrangian approach would be utilised in the initial modelling work with an Euler domain meshing the droplet geometry to cope with the predicted high levels of geometry deformation and a Lagrangian mesh applied to the stiffer target material.

A uniform hexahedral mesh was applied to the epoxy target plate with an element size of $60 \mu \mathrm{m}$ and an arbitrary tetrahedral mesh was applied to the droplet to define its volume in the applied Euler domain. The domain placed around the droplet geometry took the form of $3.2 \mathrm{~mm}$ cube with a domain cell count total of $7 \times 10^{5}$.

The interaction between the droplet and the plate was set as a frictionless contact as practised in other studies [32]. Standard earth gravity was applied to the model in the direction of the droplet impact and the target plate was constrained by fixed support on its underside.

\section{Results \& Analysis}

The analysis was conducted across a range of impact velocities with each simulation requiring a run time of approximately one hour. Figure 12 shows a contour plot of von Mises Stress in the Epoxy plate during a $140 \mathrm{~ms}^{-1}$ impact, using a cross-sectional view to detail the stress dissipation beneath the surface of the plate.
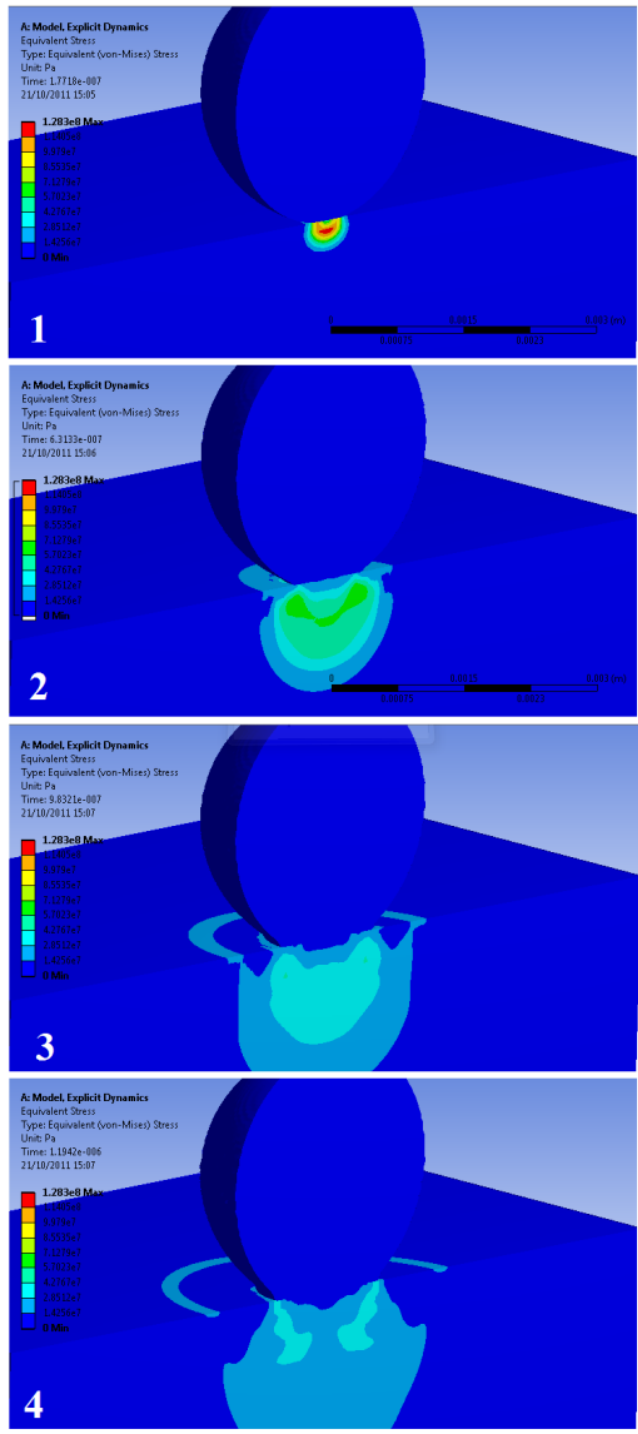

Figure 12. VON MISES STRESS CONTOURS IN EPOXY PLATE DURING $140 \mathrm{MS}^{-1}$ WATER DROP IMPACT 
From Fig. 12 it can be seen that upon initial impact, high level localised stress is created at the point of impact (pane 1) and it is at this point when the maximum stress is created. As the impact event further develops the stress begins to dissipate radially through the material resulting in a high stress rings propagating outwards from the initial impact point. However at the later stages of the impact it is still possible to observe the continuation of the creation high stress values at the periphery of the droplet contact area, thus creating a secondary inner high stress ring.

Figure 13 shows the droplet geometry in profile during impact and displays the droplet spreading behaviour upon onset of lateral jetting. This indicates that the model successfully captures the temporal and spatial aspects of the impact event.
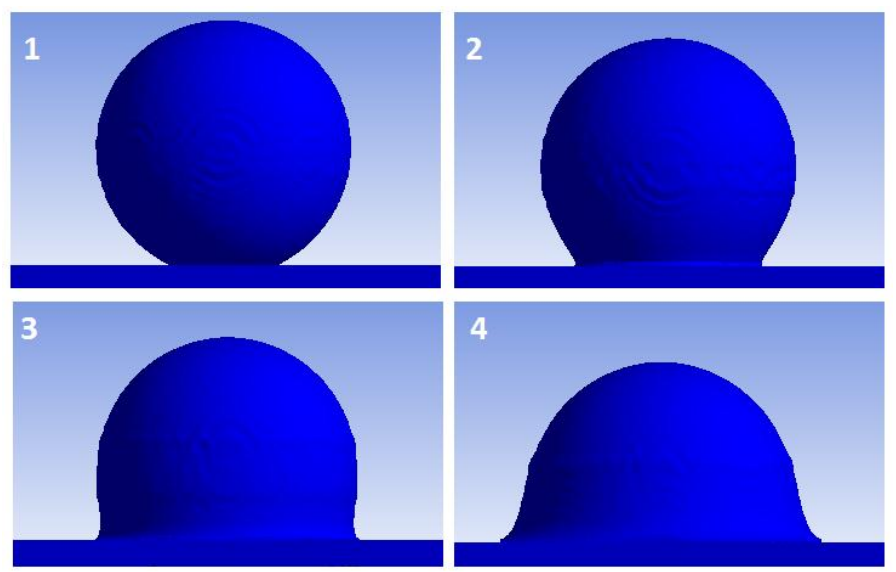

Figure 13. DROPLET SPREADING BEHAVIOUR

Figure 14 shows a time history of the values of maximum von-Mises stress in the Epoxy plate during the $140 \mathrm{~ms}^{-1}$ impact sequence.

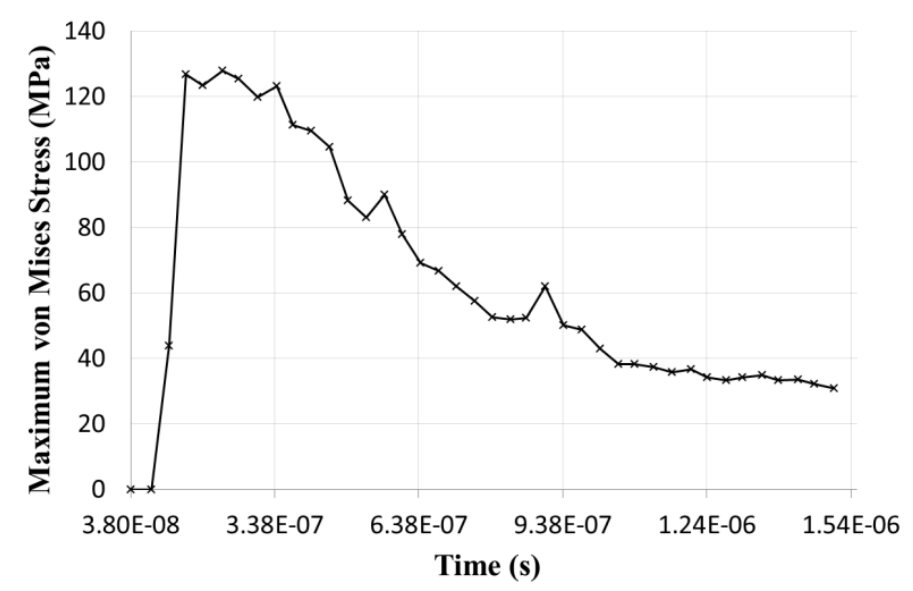

\section{Figure 14. MAXIMUM VON MISES STRESS PRESENT IN} EPOXY PLATE DURING $140 \mathrm{MS}^{-1}$ IMPACT $^{-}$

From Fig. 13 there is a clearly an observable peak initial impact stress followed by a gradual decrease. Various post-peak spikes in the stress values also occur, most notably at about $0.6 \mu \mathrm{s}$ in Fig. 14. Taking the initial impact stress across the range of simulated impact speeds and comparing these values to the theoretical impact pressures provided by the analytical expressions given in 1 (waterhammer) and 2 (modified waterhammer) gives the plot shown in Fig. 15.

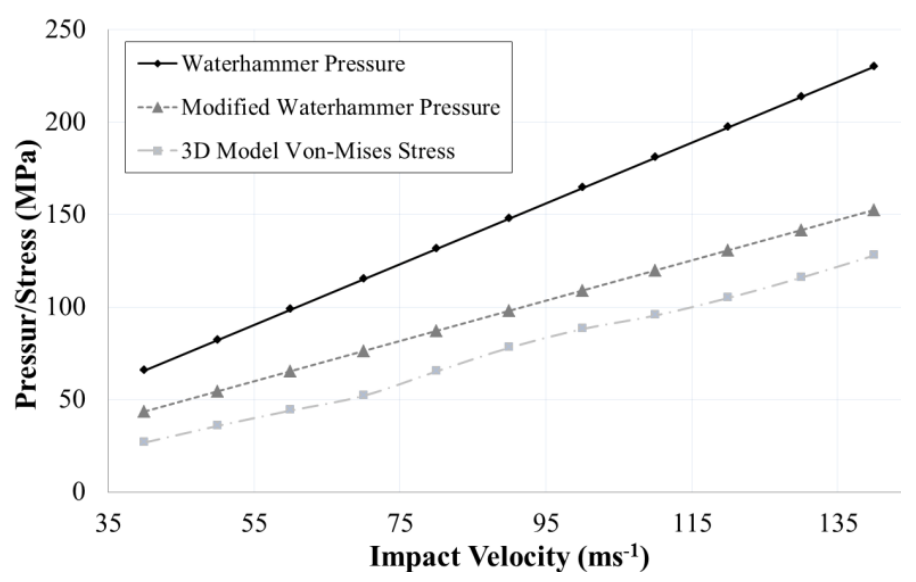

Figure 15. THEORETICAL GENERATED WATERHAMMER PRESSURE (from Eqn. 1 and Eqn. 2) COMPARED TO THE STRESS CREATED IN THE TARGET DURING IMPACT

From Fig. 15 it can be seen that the peak stresses created in the target during impact compare closely to the theoretical impact pressures given by the modified waterhammer equation (Eqn. 2) and follows a similar trend.

From each analysis it was also possible to plot the external force imparted on the target during impact. Fig. 16 shows a plot of the external force acting on the target during a $140 \mathrm{~ms}^{-1}$ impact in the direction of the impact (y-axis).

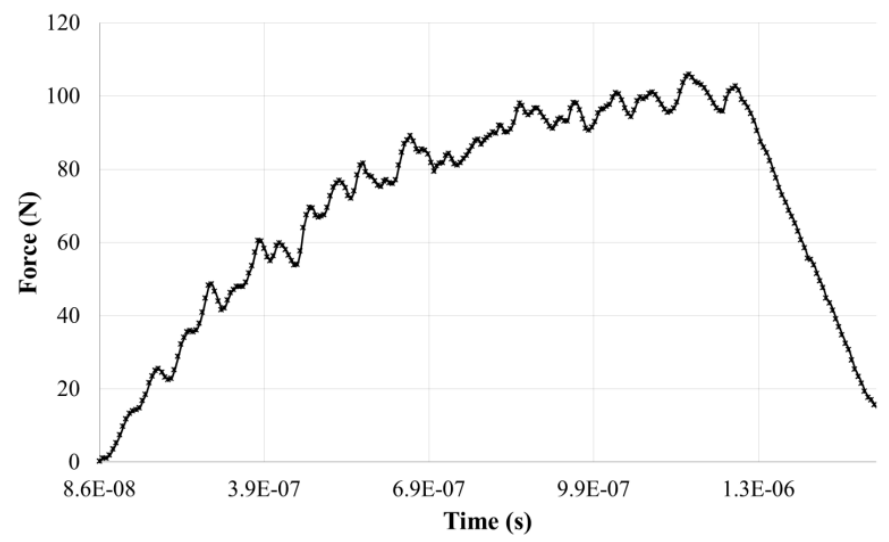

Figure 16. TARGET EXTERNAL FORCE IN Y DIRECTION (impact direction) FOR IMPACT SPEED OF 140MS ${ }^{-1}$

Using the peak values from these plots for each impact velocity and plotting them against the predicted impact force values obtained from Eqn. 3, gives the plot shown in Fig. 17. 


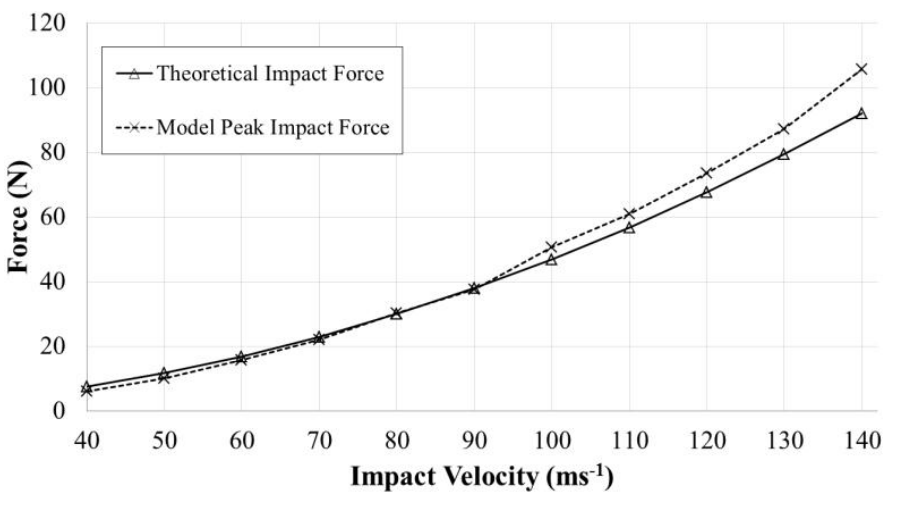

Figure 17. THEORETICAL AND MODELLED IMPACT FORCE ACROSS RANGE OF IMPACT SPEEDS

From Fig. 17 it can be seen that there is good agreement between the analytically predicted impact force values and the values obtained through the modelling process.

\section{DISCUSSION \\ Model Results}

From the results obtained it is clear that the rain drop impact modelling conducted provided results that are consistent with the standard analytical expressions (as given in Eqn. 1,2 and 3). The magnitude of the impact force simulated compares closely with the values obtained from Eqn. 3 as shown in Fig. 17; therefore indicating that the basic momentum and impact characteristics of the events simulated are accurately modelled.

The impact event development is captured in the simulations with Fig. 13 which shows the droplet impact and subsequent lateral jetting that has commonly been portrayed in the literature [32] [24] [26]. From the stress history plots as shown in Fig. 14 it is clear that there is an initial impact stress created in the target material but that there are also other subsequent stress peaks evident in the target following this event and located at the drop edge/target interface. These secondary spikes may be a result on the initiation of lateral jetting as suggested in literature [22] discussed previously) however the values reached by this peak are less than that of the initial impact stress; not (up to) 3 times greater as suggested in literature. Through further refinement of the model, this secondary peak stress may increase in magnitude, as due to the instantaneous (short-duration) nature of the event, it may be hard to fully capture in the conditions above.

The stress dissipation behaviour during impact can be said to match the theoretical behaviour as defined in literature (Fig. 7, [26]) through creating both an initial waterhammer stress (which is then dissipated through the material medium in a radial manner) and then, subsequently, a secondary inner stress concentration at the periphery of the droplet/surface contact area (Fig. 12).

Hence, the water drop impact model implemented in this study successfully simulates the water drop impact events across the range of velocities tested.

\section{Implications for Wind Turbine Blades}

From the results obtained above, it is clear that given a large enough tip speed and incident wind speed, significant forces can be imparted on leading edge materials creating stresses in the material in excess of $100 \mathrm{MPa}$ in an epoxy resin. This is considerable given that the typical compressive strength of epoxy resins can range from approximately $124-276 \mathrm{MPa}$ and tensile strengths of $28-75 \mathrm{MPa}$ [33]; the highly frequent nature of rain impact further adds its potentially damaging impact effects. It also important to note that in a real blade, the target material will be a composite (with possibly an epoxy coating) under impact in the through-thickness direction; which is the direction in which composites commonly exhibit their poorest mechanical properties. Further work would look at simulations using a composite panel/coating system as the target material to replicate a real blade construction.

\section{Further development of research in this area}

The merits of the rain drop modelling have been discussed and it is clear that there is scope for further developed. However it is important to recognise that hail stone impact will also play a key role in the performance of blade leading edge material performance. Using the same software package and through defining a hail material model, it should be possible to also simulate hail impact events. This will then allow for a more detailed and informed analysis of the impact behaviour of both rain and hail on the leading edge and allow for parametric studies to be conducted addressing issues such as impact speed, projectile size, impact angle and more.

The target material used in this study was a rudimentary epoxy resin plate, considered representative of a typical blade coating system. However in any future model development it would be prudent to create a model with a more representative coating/composite substrate target body to fully understand the material response of the blade to rain and hail impact.

The use of experimental equipment as discussed should also play an important role in validating any results obtained through simulation and would also prove valuable in further developing the understanding of any surface deterioration brought about through rain and hail impact.

\section{CONCLUSION}

A literature review looking at the effects of leading edge rain erosion and impact related issues has been conducted and the findings discussed. It was found that leading impact and erosion damage can be considering serious threats to the material integrity of wind turbine blade leading edges, especially in the hostile offshore environment. There is an absence of published literature that addresses the issue but some of the lessons learned and knowledge developed from similar aerospace studies can be considered transferrable; especially with regards to experimental work. The following objectives were then carried out:

1. A preliminary rain impact model was developed whereby through using an Explicit Dynamics software 
package a rain drop impacting on an epoxy resin plate was simulated.

2. The results obtained from the simulations were then compared to values obtained from analytical expressions, thus validating the forces and stresses created in the analyses.

3. Further development of the modelling work will involve assessing potential impact of other foreign object damage such as hail on the material surface and the material response of composite target bodies.

The outcome of the study in its present state emphasises the usefulness of the commercially available Explicit Dynamics software. The fundamental validation work carried out would suggest that the tool could be utilised furthermore in more comprehensive analyses such as: repetitive impact fatigue scenarios, studying the stress wave propagation through typical wind turbine blade cross sections (composite plies), increasing the scale of the analysis to look at a section of the leading edge under multiple impact events and many more.

The similar development of a working hail material model would also promise a great deal of further insight into the damage mechanisms of wind turbine blades.

\section{ACKNOWLEDGMENTS}

The authors are very grateful to EPSRC for sponsorship of the PhD studentship through the EPSRC funded DTC in Wind Energy, University of Strathclyde, led by Prof. William Leithead. They also wish to acknowledge Prof Leithead and Dr Francis Quail, Department of Electrical and Electronic Engineering, for helpful discussions on the work.

\section{REFERENCES}

[1] HM Government, "The UK Low Carbon Transition Plan National strategy for climate and energy," 2009.

[2] RenewableUK. (2011) www.bwea.com. [Online]. http://www.bwea.com/statistics/

[3] RenewableUK. (2010, August) Reference - FAQ. [Online]. http://www.bwea.com/ref/faq.html

[4] Wind Energy the Facts. (2011) Wind Energy the Facts. [Online]. http://www.wind-energy-the-facts.org/en/part-itechnology/chapter-3-wind-turbine-technology/evolutionof-commercial-wind-turbine-technology/large-

commercial-wind-turbines.html

[5] Wind Energy the Facts. (2011) Wind Energy the Facts. [Online]. http://www.wind-energy-the-facts.org/hu/part-itechnology/chapter-3-wind-turbinetechnology/technology-trends/tip-speed-trends.html

[6] Paul Veers, Blade Reliability Initiative, May 14, 2008.

[7] TGM Services. (2011) TGM Wind. [Online]. http://tgmwind.com/bladeerosion.html

[8] Ropeworks. (2011) Ropeworks. [Online]. http://www.ropeworks.com/service_wind_blade.htm

[9] J Zahavi and S Nadiv, "Indirect damage in composite materials due to raindrop impact," Wear, vol. 72, pp. 305313, 1981.

[10] materials.eng.cam.ac.uk. [Online]. http://wwwmaterials.eng.cam.ac.uk/mpsite/interactive_charts/specspec/NS6Chart.html

[11] LM Wind Power. (2011) lmwindpower.com. [Online]. http://www.lmwindpower.com/Blades/Technology/Design /Blade\%20concept.aspx

[12] Enercon. (2010, July) Enercon. [Online] http://www.enercon.de/p/downloads/EN_Eng_TandS_071 0.pdf

[13] Siemens. (2002-2011) energy.siemens.com. [Online]. http://www.energy.siemens.com/mx/en/powergeneration/renewables/wind-power/windturbines/\#content=Technology

[14] Ole Gunneskov, V120-4.5MW Leadership in Offshore, November 24, 2004.

[15] Zoe Barnes. (2011, May) BVGassociates. [Online]. http://www.bvgassociates.co.uk/LinkClick.aspx?fileticket $=$ ATY-pZn0xqQ\%3D\&tabid $=102$

[16] Engineers Hand Book. (2004-2006) Enginees Handbook. [Online]. http://www.engineershandbook.com/MfgMethods/polyure thanecoatings.htm

[17] Gallagher Corporation. (2011) Gallagher Corporation. [Online].

http://www.gallaghercorp.com/urethane/benefits-ofcastable-urethane.shtml

[18] 3M. (2011) 3M. [Online]. http://catalogue.3m.eu/en_EU/euwind/Tapes/3M\%E2\%84\%A2_Wind_Protection_Tapes_a nd_Accessories

[19] 3M. (2010, May) solutions.3m.com. [Online]. http://solutions.3m.com/wps/portal/3M/en_US/Renewabl e/Energy/Resources/Press_Releases/?PC_7_RJH9U52308 NR50IONISNKB32G3_assetId=1273658357891

[20] 3M. (2010) 3M. [Online]. http://multimedia. $3 \mathrm{~m} . \mathrm{com} / \mathrm{mws} /$ mediawebserver?mwsId= SSSSSu7zK1fslxtUOxmS5x_Zev7qe17zHvTSevTSeSSS SSS--\&fn=WindTapesBroch_DMR.pdf

[21] University of Dayton Research Institute. (2011) University of Dayton Research Institute. [Online]. http://www.udri.udayton.edu/NONSTRUCTURALMATE RIALS/COATINGS/Pages/RainErosionTestFacility.aspx

[22] Relius BASF. (2009) relius.de. [Online]. http://www.relius.de/en/industrie/04_windenergie/index.h tm

[23] Tesa. tesatape.com. [Online]. http://www.tesatape.com/industry/renewable_energy/wind _industry

[24] F J Heymann, "High-speed impact between a liquid drop and a solid surface," Journal of Applied Physics, vol. 40, 
no. 13, pp. 5113-5122, December 1969.

[25] J P Dear and J E Field, "High-speed photography of surface geometry effects in liquid/solid impact," Journal of Applied Physics, vol. 63, no. 4, pp. 1015-1021, Februaru 1988.

[26] A C Imeson, R Vis, and E de Water, "The measurement of water-drop impact forces with a piezo-electric transducer," CATENA, vol. 8, no. 1, pp. 83-96, 1981.

[27] M A Nearing, J M Bradford, and R D Holtz, "Measurement of Force vs. Time Relations for Waterdrop Impact," Soil Science Society of America Journal, vol. 50, no. 6, pp. 1532-1536, November-December 1986.

[28] Rui Li, Hisashi Ninokata, and Michitsugu Mori, "A numerical study of impact force caused by liquid droplet impingment onto a rigid wall," Progress in Nuclear Energy, pp. 1-5, 2011.

[29] J P Dear and J E Field, "High-speed photography of surface geometry effects in liquid/solid impact," Journal of Applied Physics, vol. 63, no. 4, pp. 1015-1021, February 1988.

[30] Marco Anghileri, Luigi M L Castelleti, Fabio Invernizzi, and Marco Mascheroni, "A survey of numerical models for hail impact analysis using explicit finite element codes," International Journal of Impact Engineering, vol. 31, pp. 929-944, October 2005.

[31] Hyonny Kim and Keith T Kedward, "Modelling Hail Ice
Impact and Predicting Impact Damage Initiation in Composite Structures," AIAA Journal, vol. 38, no. 7, pp. 1278-1288, July 2000.

[32] Edmond Tobin. (2011) University of Limerick. [Online]. http://www2.ul.ie/pdf/305950313.pdf

[33] E F Tobin, $\mathrm{T}$ M Young, Raps $\mathrm{D}$, and $\mathrm{O}$ Rohr, "Comparison of liquid impingement results from whirling arm and water-jet erosion test facilities," Wear, vol. 271, pp. 2625-2631, 2011.

[34] William F Adler, "Waterdrop Impact Modelling," Wear, vol. 186-187, pp. 341-351, 1995.

[35] Efunda. (2011) efunda.com. [Online]. http://www.efunda.com/materials/polymers/properties/pol ymer_datasheet.cfm?MajorID=epoxy\&MinorID $=2$

[36] N Dalili, A Edrisy, and R Carriveau, "A review of surface engineering issues critical to wind turbine performance," Renewable and Sustainable Energy Reviews, vol. 13, pp. 428-438, 2009. 